\title{
Silylation of titanium-containing amorphous silica catalyst: Effect on the alkenes epoxidation with $\mathrm{H}_{2} \mathrm{O}_{2}$
}

\author{
M. C. Capel-Sanchez*, J. M. Campos-Martin, J. L. G. Fierro \\ Sustainable Energy and Chemistry Group (EQS), Instituto de Catálisis y Petroleoquímica, \\ CSIC, Marie Curie, 2, Cantoblanco, 28049 Madrid. Spain http://www.icp.csic.es/eqs/ \\ *Corresponding Author: e-mail: mcapel@icp.csic.es
}

\begin{abstract}
The surface of a $\mathrm{Ti} / \mathrm{SiO}_{2}$ catalyst was silylated using hexamethyldisilazane (HMDS) and tetramethyldisilazane (TMDS) as silylating reagents in vapor phase. The silylation of silanol (Si-OH) on the catalysts was confirmed by diffuse reflectance UV-Vis, DRIFT spectroscopy and solid-state ${ }^{29} \mathrm{Si}$ MAS NMR techniques. Silylation with TMDS improves the catalytic performance of $\mathrm{Ti} / \mathrm{SiO}_{2}$ catalyst more significantly than with HMDS and this is mainly due to the steric bulk effects of trimethylsilyl groups from HMDS as compared to dimethylsilyl groups from TMDS. The silylation degree with TMDS was found to be higher than with HMDS and no changes in the silylation degree with TMDS was observed for silylation times longer than $2 \mathrm{~h}$. Despite the silylation route employed, the silylated surface is hydrophobic which enhances not only in hydrogen peroxide efficiency but also and in selectivity to epoxide in the epoxidation of alkenes with $\mathrm{H}_{2} \mathrm{O}_{2}$. These effects are more evident when the hydrogen peroxide concentration is higher and particularly for the catalyst modified with TMDS.
\end{abstract}

Keywords: Silylation, $\mathrm{Ti} / \mathrm{SiO}_{2}$ catalysts, 1-octene, cyclohexene, epoxidation, Hydrogen peroxide. 


\section{INTRODUCTION}

Despite numerous reports in the literature, the epoxidation of terminal alkenes remains a challenge in petrochemistry. Many different methods have been developed for the preparation of epoxides. A large body of work has been generated on titanium-substituted zeolites in the framework, including TS-1, Ti- $\beta$, Ti-incorporated ordered mesoporous silica and amorphous xerogels, which have been extensively investigated [1, 2]. An interesting alternative is the use of $\mathrm{Ti} / \mathrm{SiO}_{2}$ catalysts [3-7] because these catalysts are relatively inexpensive, easy to synthesize and regenerate, and at the same time show high conversion rates. Notwithstanding, the activity and selectivity of mesoporous Ti-containing materials reported so far is not as high as expected in oxidizing relatively less bulky organic substrates compared to that exhibited by TS-1.

The poor performance of Ti(IV) sites supported on mesoporous silicas in the epoxidation of alkenes with aqueous hydrogen peroxide has been attributed to the chemical properties of the support surface $[8,9]$. The catalyst surface is hydrophilic, and the Ti(IV) site is presumably deactivated by the competitive binding of water molecules, which hinder formation of the key titanium-hydroperoxide intermediate. There is considerable interest in this problem, since aqueous hydrogen peroxide is a desirable oxidant that yields an environmentally benign by-product $\left(\mathrm{H}_{2} \mathrm{O}\right)$ [10]. Therefore, an enhancement of the hydrophobicity is considered important to improve the activity of $\mathrm{Ti} / \mathrm{SiO}_{2}$ and retard the $\mathrm{Ti}$ leaching in liquid phase oxidation. Moreover, water removal from the catalyst surface would also reduce the hydrolysis of the epoxide product and, therefore, would be beneficial for the selectivity of the reaction. An increased hydrophobicity of the catalyst surface is also expected to favour the diffusion of the rather apolar alkene substrates inside the pores of the catalyst [11]. The hydrophobicity of mesoporous silica should be increased by removing the unnecessary hydroxyl groups or replacing them by other groups, which will facilitate the condensation of organic compounds in the pores. A common practice is to cover the surface with a layer of a silylant agent that is selectively hydrolyzed by these hydroxyl groups by covalently bonding organic groups to the inorganic siliceous framework, i.e. substitution of $\mathrm{Si}-\mathrm{OH}$ by $\mathrm{Si}-\mathrm{O}-\mathrm{SiR}(\mathrm{R}=$ organic chain) $[12,13]$. Silylation of the catalyst surface is an outstanding procedure for improving both the activity and selectivity of epoxidation 
reactions $[14,15]$. Several silylating agents have been used and hexamethyldisilazane has proven to be one of the most efficient $[12,16]$.

In the present work, we investigate a new silylating agent 1,1,3,3- tetramethyldisilazane (TMDS), to modify $\mathrm{Ti} / \mathrm{SiO}_{2}$ catalysts. The silylation efficiency of this new agent was compared to 1,1,1,3,3,3-hexamethyldisilazane (HMDS). Different levels of silylation were obtained by varying the reaction time. With this aim we developed a simple method for the silylation of a $\mathrm{Ti} / \mathrm{SiO}_{2}$ catalyst. It was also evaluated the effect that the degree of silylation produces on the activity and the selectivity in the 1-octene epoxidation reaction with hydrogen peroxide.

\section{EXPERIMENTAL METHODS}

Catalysts were prepared by the procedure already reported in the literature [7]. Titanium (triethanolaminate) isopropoxide $\left(\mathrm{TYZOR}^{\circledR} \mathrm{TE}\right)(2.0 \mathrm{mmol})$ was dispersed in 2-propanol (25 $\mathrm{ml}$ ), the solution was heated to $353 \mathrm{~K}$ under stirring and then $5 \mathrm{~g}$ of silica (Grace Davison, XPO 2407) were added and the suspension was stirred for $2 \mathrm{~h}$. The solid was filtered out and washed twice with $25 \mathrm{ml}$ of 2-propanol, dried at $383 \mathrm{~K}$, and finally calcined at $773 \mathrm{~K}$ for $5 \mathrm{~h}$. Two silylant reagents: 1,1,1,3,3,3-hexamethyldisilazane (HMDS) and 1,1,3,3tetramethyldisilazane (TMDS) were used for the silylation of samples. The procedure was as follows: the silylant reagent fed continuously by a syringe pump to a continuous flow of $\mathrm{N}_{2}$ on the sample bed with a temperature of $473 \mathrm{~K}$ for 2 or $16 \mathrm{~h}$, then a nitrogen flow was fed for $2 \mathrm{~h}$. The silylation reagent/catalyst weight ratio was of 0.23 and 1.60 , respectively.

The titanium content of the $\mathrm{Ti} / \mathrm{SiO}_{2}$ of the catalysts was determined using inductively coupled plasma absorption spectrometry, with a Perkin-Elmer Optima 3300 DV instrument. The amount of titanium in the $\mathrm{Ti} / \mathrm{SiO}_{2}$ catalyst prepared was approximately $1 \%$ weight. Elemental analyses (CHN) were performed with a LECO CHNS-932 equipment.

Textural properties were determined from the adsorption-desorption isotherms of nitrogen recorded at $77 \mathrm{~K}$ with a Micromeretics TriStar 3000. Specific area was calculated by applying the $B E T$ method to the relative pressure $\left(P / P_{0}\right)$ range of the isotherms between 0.03 and 0.3 , taking a value of $0.162 \mathrm{~nm}^{2}$ for the cross-section of adsorbed nitrogen molecule at $77 \mathrm{~K}$. Pore size distributions were computed by applying the Barrett-Joyner-Halenda (BJH) model to the desorption branch of the nitrogen adsorption-desorption isotherms. 
Ultraviolet-visible spectra were measured on a Varian Carry 5000 UV-Vis spectrophotometer equipped with an integrating sphere. $\mathrm{A} \mathrm{BaSO}_{4}$ disc-sample was used as reference. All spectra were acquired under ambient conditions. Diffuse reflectance infrared Fourier transform spectra (DRIFTS) were recorded at room temperature on a Jasco 6300 FTIR spectrophotometer. The instrument incorporated an integration sphere and a Harrick HVCDRP environmentally-controlled cell. About $50 \mathrm{mg}$ of the powdered sample was packed into a sample holder and dried in situ at 423,523 and $623 \mathrm{~K}$ for $1 \mathrm{~h}$ while a helium flow (Air Liquid) was passed through the sample. A DRIFT spectrum of dry $\mathrm{KBr}$ was also recorded as background. For each sample, 100 scans were accumulated at a spectral resolution of $4 \mathrm{~cm}^{-1}$. Solid-state ${ }^{29}$ Si CP-MAS NMR with ${ }^{1} \mathrm{H}$ decoupling measurements were recorded on a Bruker AMX 300 spectrometer. The dried powdered samples were loaded into a 4-mm multinuclear probe $\mathrm{BL} 4 \mathrm{X} / \mathrm{Y} / 1 \mathrm{H}$ and spun at $10 \mathrm{kHz}$ according to the following protocol: $\pi / 2$ pulse, $7 \mu \mathrm{s} ; \mathrm{CP}$ contact time $2 \mathrm{~ms}$; high power $\mathrm{H}$-decoupling during detection; a repetition delay of $30 \mathrm{~s}$; and 2000 scans. An internal reference of the spectrometer was employed to calculate the chemical shifts.

The catalytic activity was performance in a typical run, a suspension of alkene (0.2 mol), tertbutanol $(11 \mathrm{~g})$ and $1 \mathrm{~g}$ of catalyst were heated at $333 \mathrm{~K}$, and then an organic solution of $5 \mathrm{wt}$ $\%$ of $\mathrm{H}_{2} \mathrm{O}_{2}$ (in tert-butanol) was added to the reaction vessel during $30 \mathrm{~min}$. Hydrogen peroxide concentrations, referred to the whole final reaction mixture tested, were 0.6 and 1.2\%. The $\mathrm{H}_{2} \mathrm{O}_{2}$ /substrate molar ratios were $0.01: 0.2$ for $0.6 \%$ of $\mathrm{H}_{2} \mathrm{O}_{2}$ and $0.02: 0.2$ for $1.2 \%$ $\mathrm{H}_{2} \mathrm{O}_{2}$ concentration. The organic compounds were analyzed by GC-FID (Agilent 6850, equipped with a HP-WAX capillary column). The hydrogen peroxide was measured by standard iodometric titration.

\section{RESULTS AND DISCUSSION}

\section{Catalysts Characterization}

The reaction between $\mathrm{Ti} / \mathrm{SiO}_{2}$ silanol groups and silylating agent produces $\mathrm{NH}_{3}$ according to Scheme 1 with HMDS and Scheme 2 with TMDS.

The corresponding specific BET surface areas, pore diameters and pore volumes of the catalysts are shown in Table 1. The silylation process brought about a slight decrease in the 
nitrogen adsorption capacity, reflected in a decrease in the values of specific areas of all the silylated catalysts. Thus, the value of specific BET surface area of the reference catalyst $213 \mathrm{~m}^{2} \mathrm{~g}^{-1}$-decreased to approximately $193 \mathrm{~m}^{2} \mathrm{~g}^{-1}$ in silylated catalysts. A parallel decrease in pore volume was also observed. The reduction in pore volume appears to be related to the texture of the reference catalyst, since coating of the silica particles results in an increase in the size of the agglomerates or packed particles, eliciting a decrease in the adsorption capacity of the silylated samples. In addition, pore size distribution, as determined by applying the BJH model to the desorption branch of the nitrogen adsorption-desorption isotherms, also underwent some changes. The pore sizes of the silylated samples decreased slightly with respect to the reference catalyst. All the silylated samples displayed similar decrease in both the specific surface area and in the pore size. According to the homogeneous pore size distributions and the pore size of the samples after silylating of the catalysts the ammonia does not damage the porous structure of the catalyst.

The electronic spectra of the samples showed an absorption associated with the ligand metal-charge transfer (LMCT) from the oxygen to an empty orbital of the Ti(IV) ion: $\mathrm{Ti}^{4+} \mathrm{O}^{2-}$ $\rightarrow \mathrm{Ti}^{3+} \mathrm{O}^{-}$typical of this type of catalysts. The wavelength at which this transition occurs is highly sensitive to the coordination of titanium sites, and accordingly it has been often considered as a probe to test titanium coordination $[17,18]$. The UV-vis spectra show absorption at wavelengths in the region $200-300 \mathrm{~nm}$, which is characteristic of this type of catalyst. Two components can be identified in this absorption band: the most intense one is placed around $210 \mathrm{~nm}$, typical of isolated Ti(IV) ions in a tetrahedral environment of oxide ions [17], and a second, broader band located at somewhat higher wavelengths (ca. 250 $\mathrm{nm}$ ), originated from tetrahedral titanium species coordinated with water molecules [17, 18]. It has been shown that the component at ca. $250 \mathrm{~nm}$ disappears upon sample calcination thus avoiding interference of these isolated penta-coordinated Ti centers [7]. Both titanium species are the active sites of $\mathrm{Ti} / \mathrm{SiO}_{2}$ catalysts for oxidation reactions. In addition, the presence of small Ti-O-Ti oligomers (275-300) [18] or small $\mathrm{TiO}_{2}$ cluster (370$410 \mathrm{~nm})[19]$ is precluded.

UV-vis spectra of the two silylated samples (TMDS and HMDS) and the corresponding nonsilylated counterpart are included in Figure 1. It is emphasized here that the UV-Vis spectra were recorded under ambient conditions, thus the amount of adsorbed water on the surface 
depends on the hydrophobic/hydrophilic character of the surface. Accordingly, the intensity of the band at $250 \mathrm{~nm}$ is related with the hydrophilic character of the surface. These observations cannot be made if the UV-Vis spectra were recorded under dry atmosphere. At a first glance comparison of these spectra shows no significant differences although a careful scrutiny of the 250-275 nm energy region, where the adsorption of tetrahedral species of titanium coordinated with water usually appears [17, 18], reveals some differences. The intensity of the absorption bands of silylated samples is somewhat lower than the nonsilylated one because its hydrophilic character has been inhibited to some extent by the chemically grafted surface layer by TMDS and HMDS silylant agents, thus reducing the affinity for water molecules $[17,18]$. It is also observed that the silylating degree is somewhat higher in the catalyst silylated with TMDS. This observation is consistent with the sterical hindrance of silyl groups, which makes the silylation efficiency to be higher for TMDS than for HMDS [20]. Besides, as the samples silylated for 2 and $16 \mathrm{~h}$ displayed essentially the same electronic spectra, it is inferred that silylation is a quick process.

DRIFT spectra of non-silylated, silylated samples and the bare silica, used to prepare the samples, degassed at room temperature and at various pre-treatment temperatures are presented in Figure 2. All the spectra at room temperature show a broad band in the $\mathrm{OH}$ stretching vibration energy region (3600-2500 $\mathrm{cm}^{-1}$ ) associated with water molecules interacting with surface $\mathrm{OH}$ groups $[4,16]$. An increase in the degassing temperature leads to the removal of water molecules adsorbed on the surface (Figure 2) [16]. Adsorbed water was fully removed at $623 \mathrm{~K}$. DRIFT spectra of the samples degassed at $623 \mathrm{~K}$ are displayed in Figure 3. The reference sample shows a band at about $3700 \mathrm{~cm}^{-1}$, which belongs to the stretching vibration mode of terminal or geminal silanol group. This band disappears in silylated samples, which is a clear indication of the chemical reaction between the organosilane reagent and the terminal and geminal silanol groups [12]. The broad absorption band between $3600-3400 \mathrm{~cm}^{-1}$ corresponds to H-bonded hydroxyl groups. For the HM sample, the residual geminal silanols still remaining after silylation most likely originates from partial silylation of an aggregate of hydrogen-bonded silanol groups. The reaction of HMDS with these residual silanol groups may be sterically hindered by the presence of neighbouring trimethylsilyl groups [20]. The DRIFT spectra of the silylated catalysts show the typical stretching vibration bands of $\mathrm{C}-\mathrm{H}$ bonds between 3000 and 2800 
$\mathrm{cm}^{-1}$ corresponding to the $-\mathrm{CH}_{3}$ groups formed during the silylation process [16]. The sample silylated with TMDS shows an additional peak at $2200 \mathrm{~cm}^{-1}$ due to the presence of Si-H bonds. As already shown by the electronic spectra, no differences between the DRIFT spectra of the samples silylated for 2 and $16 \mathrm{~h}$ were observed.

Solid-state ${ }^{29} \mathrm{Si}$ MAS NMR spectra (Figure 4) confirmed the presence of $-\mathrm{SiCH}_{3}$ groups bound to the surface of the silylated samples. Distinct resonances can be clearly distinguished: $Q^{4}$ and $\mathrm{Q}^{3}$ are responsible for $\mathrm{Si}$ bonded to 4 siloxane $\left[(-\mathrm{OSi})_{4}\right]$ and three siloxane groups and one hydroxyl group [(-SiO) $\left.{ }_{3} \mathrm{SiOH}\right]$, respectively [11]. For the HM silylated sample, a new signal was detected at $9.5 \mathrm{ppm}$, assigned to $\left(\mathrm{CH}_{3}\right)_{3} \mathrm{Si}-\mathrm{O}$ [20], whereas for TM sample this new signal is placed at $-14 \mathrm{ppm}$ and assigned to $\left(\mathrm{CH}_{3}\right)_{2} \mathrm{HSi}-\mathrm{O}$ [20]. These spectral features clearly show that the silylant agent reacts with surface silanol groups, which makes the catalyst surface hydrophobic. The intensities of $Q^{3}$ and $Q^{4}$ components were estimated by calculating the integral of each peak and then an estimate of the extent of sample silylation was made by calculating the ratio between the peak area of $Q^{3}$ and $Q^{4}$ components (Table 2). The relative area of $Q^{3}$ and $Q^{4}$ components depend on the silylating treatment. The decrease of the relative area of $Q^{3}$ component in silylated samples with respect the non-silylated one is a consequence of the disappearance of surface $\mathrm{Si}-\mathrm{OH}$ groups by chemical reaction with silylant agent to form $\left(\mathrm{CH}_{3}\right)_{2} \mathrm{HSi}-\mathrm{O}-\mathrm{Si}$ or $\left(\mathrm{CH}_{3}\right)_{3} \mathrm{Si}-\mathrm{O}-\mathrm{Si}$ moieties. Such a drop is more evident for the samples silylated with TMDS. Indeed, these observations have been confirmed by elemental analysis (Table 2). After silylation, $-\mathrm{CH}_{3}$ groups are present on the catalyst surface and accordingly the surface density of these groups depends on the silylation degree. The sample silylated with TMDS has a higher carbon amount than that silylated with HMDS; this difference is even more pronounced considering that HMDS incorporates $3 \mathrm{C}$-atoms while TMDS incorporates only two C-atoms at each silylation centre. This result confirms that silylation is more effective by using TMDS instead HMDS. The silylation efficiency decreased according to the sterical hindrance of the silyl groups which is higher for HMDS than for TMDS [20].

\section{Catalytic Activity}

The two silylated catalysts and the non-silylated counterpart were tested in the liquid phase epoxidation reaction of two alkenes using hydrogen peroxide as oxidant. For this purpose 
two olefinic substrates were selected: 1-octene and cyclohexene. As a primary alkene, 1octene is difficult to epoxidize but the epoxide is relatively stable (1-octene), however cyclohexene is relatively easy to epoxidize but its epoxide is more reactive and consequently it can be hydrolyzed to the corresponding glycol.

The 1-octene epoxidation was performed using two hydrogen peroxide concentrations, referred to the whole reaction mixture ( $0.6 \mathrm{wt} \%$ and $1.2 \mathrm{wt} \%)$ by adding dropwise the oxidant solution during the first 30 min of the reaction. The slow addition of $\mathrm{H}_{2} \mathrm{O}_{2}$ is crucial to avoid, or at least minimize, the useless decomposition of the oxidant and to keep the local water concentration as low as possible [3-7, 21]. The conversion was very high for all three samples and no other products than 1-octene epoxide were detected. For the lowest $\mathrm{H}_{2} \mathrm{O}_{2}$ concentration (0.6 wt \%) all samples reached very high hydrogen peroxide efficiency (Figure 5). At this low $\mathrm{H}_{2} \mathrm{O}_{2}$ concentration, there is not apparent improvement in catalyst performance. However, when high $\mathrm{H}_{2} \mathrm{O}_{2}$ peroxide concentration is employed (1.2 wt \%), some differences among samples are observed. For all samples a small decrease in the hydrogen peroxide efficiency is observed. The efficiency decrease for the non-silylated sample is very important ( $90 \%$ to $55 \%$ ), while the decrease in the silylated samples is clearly lower. In addition, some differences are observed when comparing the two silylated samples. In general, the catalyst silylated with TMDS yields higher efficiency than catalyst silylated with HMDS. This trend is the same than that of the silylation degree derived from UV-vis, DRIFT and ${ }^{29}$ Si MAS NMR spectroscopic results and also by the hydrogen peroxide efficiency in the epoxidation of 1-octene. In addition, there is no influence of the silylation time of the catalysts with TMDS on the performance in the target reactions, suggesting that the silylation reaction is very quick. On the contrary, the catalyst silylated with HMDS at different times displayed some differences in the performance. These results suggest that HMDS silylation is slower than with TMDS as indicated by the improvement of the hydrogen peroxide efficiency achieved with catalysts already silylated for longer periods of time.

Similarly, the cyclohexene epoxidation was performed using two hydrogen peroxide concentrations (0.6 wt. \% and $1.2 \mathrm{wt}$. \%) and the oxidant solution was also dropwise added during the first $30 \mathrm{~min}$ of the reaction. In this reaction, the desired product is cyclohexene oxide and the potential by-products are 2-cyclohexen-1-ol and 1,2-cyclohexanediol [21]. For all catalysts and $\mathrm{H}_{2} \mathrm{O}_{2}$ concentration studied in this work the oxidant conversion was 
complete. For the two hydrogen peroxide concentrations employed the oxidant efficiency was very high (Figure 6). For all samples an increase in the amount of hydrogen peroxide added to the reaction produces an increase in $\mathrm{H}_{2} \mathrm{O}_{2}$ efficiency. Silylated samples show a higher $\mathrm{H}_{2} \mathrm{O}_{2}$ efficiency and the one silylated with TMDS yields higher efficiency than that silylated with HMDS. Similarly to 1-octene epoxidation, some differences in the performance of the catalyst silylated with HMDS at different times have been observed. Again, these results indicate a close relationship between silylation degree revealed by UV-vis, DRIFT and ${ }^{29} \mathrm{Si}$ MAS NMR techniques and hydrogen peroxide efficiency in the epoxidation of cyclohexene.

Along the epoxidation reaction of cyclohexene two by-products were observed. Accordingly, the effect of catalyst silylation can be studied as a function of the amounts of hydrogen peroxide added to the reactor. In general, the selectivity to epoxide decreased with increasing concentration of hydrogen peroxide (Figure 7). This selectivity drop was less pronounced for the silylated sample than for the non-silylated one.

This decrease in the selectivity to the epoxide is related with the amount of water present in the reaction mixture; as water is the by-product of hydrogen peroxide reaction, the greater amount of $\mathrm{H}_{2} \mathrm{O}_{2}$ added gives the higher final water concentration. The water molecules adsorbed in the catalyst surface may react with epoxide via epoxirane ring-opening reaction, leading to glycols (diols) [21]. The epoxide ring-opening side reaction is catalyzed mainly by the acidic titanium sites [22]. Changes in the surface properties produced by silylation not only affect the acidity of the surface but also improve the hydrophobicity of the catalyst surface. This changes in the surface properties yield to a better performance in the catalytic centre, because the hydrophobicity of the surface repel water formed far from isolated tetrahedral Ti(IV) centers. This effect produce an increase in the catalytic activity by keeping the adsorption site free of water and reducing the oxirane group hydrolysis because the amount of water molecules close to the Ti sites is lower. For these reasons, the extent of glycol formation is lower in silylated samples, and samples silylated with TMDS yield higher epoxide selectivity than that silylated with HMDS. The selectivity of catalyst silylated with HMDS was found to increase with silylation time, that is, the better selctivity was achieved with the catalysts silylated for the longest time. 


\section{CONCLUSIONS}

Vapor-phase silylation of Ti-loaded amorphous silica epoxidation catalysts has been successfully achieved with TMDS and HMDS agents. The UV-vis, DRIFT and ${ }^{29}$ Si CP-MAS NMR techniques provide useful information on the silylation degree of the catalysts. The experimental results indicate that the silylating agent TMDS improves the catalytic performance of $\mathrm{Ti} / \mathrm{SiO}_{2}$ catalyst more significantly than the previously reported agent, HMDS, and this is mainly due to the steric bulk effects of the silylating groups, that is to say because of the bulky trimethylsilyl groups from HMDS versus dimethylsilyl groups from TMDS. The silylation degree with TMDS was found to be higher than with HMDS and no changes in the silylation degree with TMDS was observed for silylation times longer than $2 \mathrm{~h}$. On the contrary, the slower silylation degree observed for HMDS implies necessarily long reaction times to achieve high silylation degrees. The silylation of $\mathrm{Ti} / \mathrm{SiO}_{2}$ catalysts led to changes in their performance for the epoxidation of alkenes (1-octene and cyclohexene) with dilute hydrogen peroxide solutions. Silylation treatment enhanced catalyst hydrophobicity producing an increase in the hydrogen peroxide efficiency and epoxide selectivity and these effects were more evident by using higher hydrogen peroxide concentrations. The $\mathrm{H}_{2} \mathrm{O}_{2}$ efficiency and selectivity to epoxide were higher for the catalysts silylated with TMDS, which in turn displayed a higher sylilation degree. 


\section{REFERENCES}

[1] D.E. De Vos, B.F. Sels and P.A. Jacobs, Adv. Synth. Catal., 345 (2003) 457.

[2] P. Ratnasamy, D. Srinivas and H. Knözinger, Adv. Catal., 48 (2004) 1.

[3] M.C. Capel-Sanchez, J.M. Campos-Martin, J.L.G. Fierro, M.P. De Frutos and A. Padilla Polo, Chem. Commun., (2000) 855.

[4] M.C. Capel-Sanchez, J.M. Campos-Martin and J.L.G. Fierro, J. Catal., 217 (2003) 195.

[5] A. Campanella, M.A. Baltanas, M.C. Capel-Sanchez, J.M. Campos-Martin and J.L.G. Fierro, Green Chem., 6 (2004) 330.

[6] M.C. Capel-Sanchez, J.M. Campos-Martin and J.L.G. Fierro, J. Catal., 234 (2005) 488.

[7] M.C. Capel-Sanchez, G. Blanco-Brieva, J.M. Campos-Martin, M.P. De Frutos, W. Wen, J.A. Rodriguez and J.L.G. Fierro, Langmuir, 25 (2009) 7148.

[8] A. Corma, P. Esteve and A. Martinez, J. Catal., 161 (1996) 11.

[9] T. Tatsumi, K.A. Koyano and N. Igarashi, Chem. Commun., (1998) 325.

[10] J.M. Campos-Martin, G. Blanco-Brieva and J.L.G. Fierro, Angew. Chem. Int. Ed., 45 (2006) 6962.

[11] K.F. Lin, P.P. Pescarmona, K. Houthoofd, D.D. Liang, G. Van Tendeloo and P.A. Jacobs, J. Catal., 263 (2009) 75 .

[12] N.R.E.N. Impens, P. van der Voort and E.F. Vansant, Microporous Mesoporous Mater., 28 (1999) 217.

[13] M.R. Prasad, M.S. Hamdy, G. Mul, E. Bouwman and E. Drent, Journal of Catalysis, 260 (2008) 288.

[14] R.L. Brutchey, D.A. Ruddy, L.K. Andersen and T.D. Tilley, Langmuir, 21 (2005) 9576.

[15] N. Igarashi, S. Kidani, R. Ahemaito, K. Hashimoto and T. Tatsumi, Microporous Mesoporous Mater., 81 (2005) 97.

[16] M.C. Capel-Sanchez, L. Barrio, J.M. Campos-Martin and J.L.G. Fierro, Journal of Colloid and Interface Science, 277 (2004) 146.

[17] V.A. De La Peña O'Shea, M. Capel-Sanchez, G. Blanco-Brieva, J.M. Campos-Martin and J.L.G. Fierro, Angew. Chem. Int. Ed., 42 (2003) 5851.

[18] M.C. Capel-Sanchez, V.A. De la Peña-O'Shea, L. Barrio, J.M. Campos-Martin and J.L.G. Fierro, Top. Catal., 41 (2006) 27.

[19] L. Marchese, E. Gianotti, V. Dellarocca, T. Maschmeyer, F. Rey, S. Coluccia and J.M. Thomas, Phys. Chem. Chem. Phys., 1 (1999) 585.

[20] Y. Liang and R. Anwander, J. Mater. Chem., 17 (2007) 2506.

[21] M. Guidotti, C. Pirovano, N. Ravasio, B. Lazaro, J.M. Fraile, J.A. Mayoral, B. Coq and A. Galarneau, Green Chem., 11 (2009) 1421.

[22] C.A. Muller, M.S. Schneider, T. Mallat and A. Baiker, Journal of Catalysis, 192 (2000) 448. 
Scheme 1

Silylation scheme with HMDS

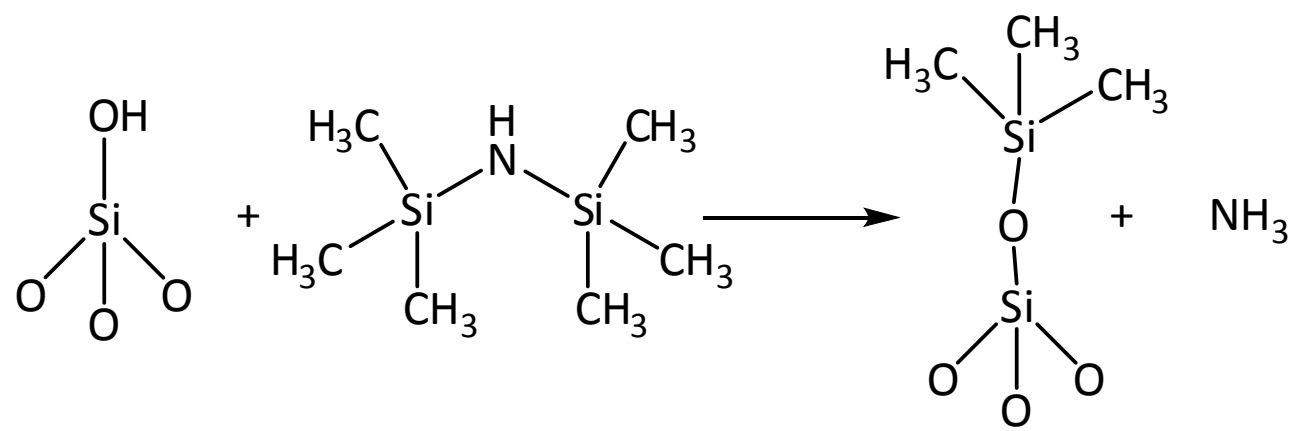

Scheme 2

Silylation scheme with TMDS<smiles>C[C@@H](CC[SiH](C)N[SiH](C)C)O[Si]([O-])([O-])O</smiles> 
Table 1. Textural properties of the catalysts

\begin{tabular}{|c|c|c|c|}
\cline { 2 - 4 } & $\begin{array}{c}\text { BET area } \\
\left(\mathrm{m}^{2} \mathrm{~g}^{-1}\right)\end{array}$ & $\begin{array}{c}\text { Pore diameter } \\
(\mathrm{nm})\end{array}$ & $\begin{array}{c}\text { Pore volume } \\
\left(\mathrm{cm}^{3} \mathrm{~g}^{-1}\right)\end{array}$ \\
\hline Reference & 213 & 23.0 & 1.37 \\
\hline HM 2 & 198 & 22.1 & 1.25 \\
\hline HM 16 & 200 & 22.3 & 1.28 \\
\hline TM 2 & 199 & 22.4 & 1.26 \\
\hline TM 16 & 193 & 22.1 & 1.24 \\
\hline
\end{tabular}

Table 2. Chemical analysis of the catalysts

\begin{tabular}{|c|c|c|c|c|}
\hline & $\% \mathrm{C}$ & $\% \mathrm{H}$ & $\% \mathrm{~N}$ & $\mathrm{Q}^{3} / \mathrm{Q}^{4}$ \\
\hline Reference & - & - & - & 0.081 \\
\hline $\mathrm{HM}$ & 1.85 & 0.73 & 0.03 & 0.045 \\
\hline $\mathrm{TM}$ & 2.20 & 0.86 & 0.07 & 0.039 \\
\hline
\end{tabular}




\section{CAPTION TO FIGURES}

Figure 1. Diffuse reflectance UV-vis spectra of the samples.

Figure 2. DIRFT spectra in the $\mathrm{OH}$ vibration region of the samples degassed at different temperatures.

Figure 3. DIRFT spectra in the of $\mathrm{OH}$ vibration region of the samples dried at $623 \mathrm{~K}$.

Figure 4. $\quad{ }^{29} \mathrm{Si}$ CP-MAS NMR spectra of samples under ambient conditions.

Figure 5. Hydrogen peroxide efficiency after $1 \mathrm{~h}$ of reaction $(\mathrm{T}=353 \mathrm{~K}$ ) in the epoxidation of 1-octene with two hydrogen peroxide concentrations.

Figure 6 Hydrogen peroxide efficiency after $1 \mathrm{~h}$ of reaction $(T=353 \mathrm{~K}$ ) in the epoxidation of cyclohexene with two hydrogen peroxide concentrations.

Figure 7. Selectivity after $1 \mathrm{~h}$ of reaction $(T=353 \mathrm{~K})$ to different products in the epoxidation of cyclohexene with hydrogen peroxide. 


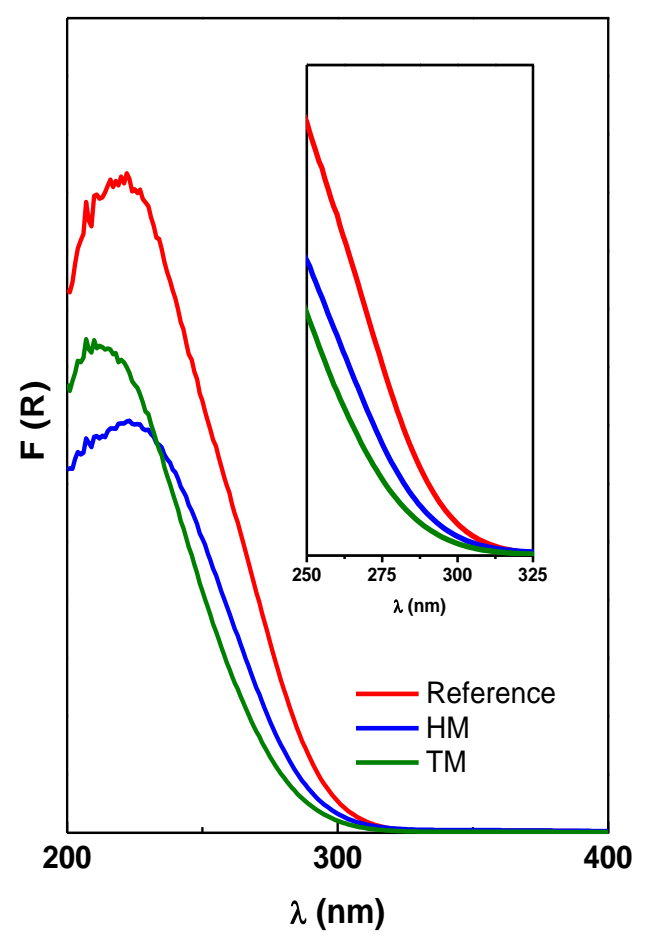

Figure 1 


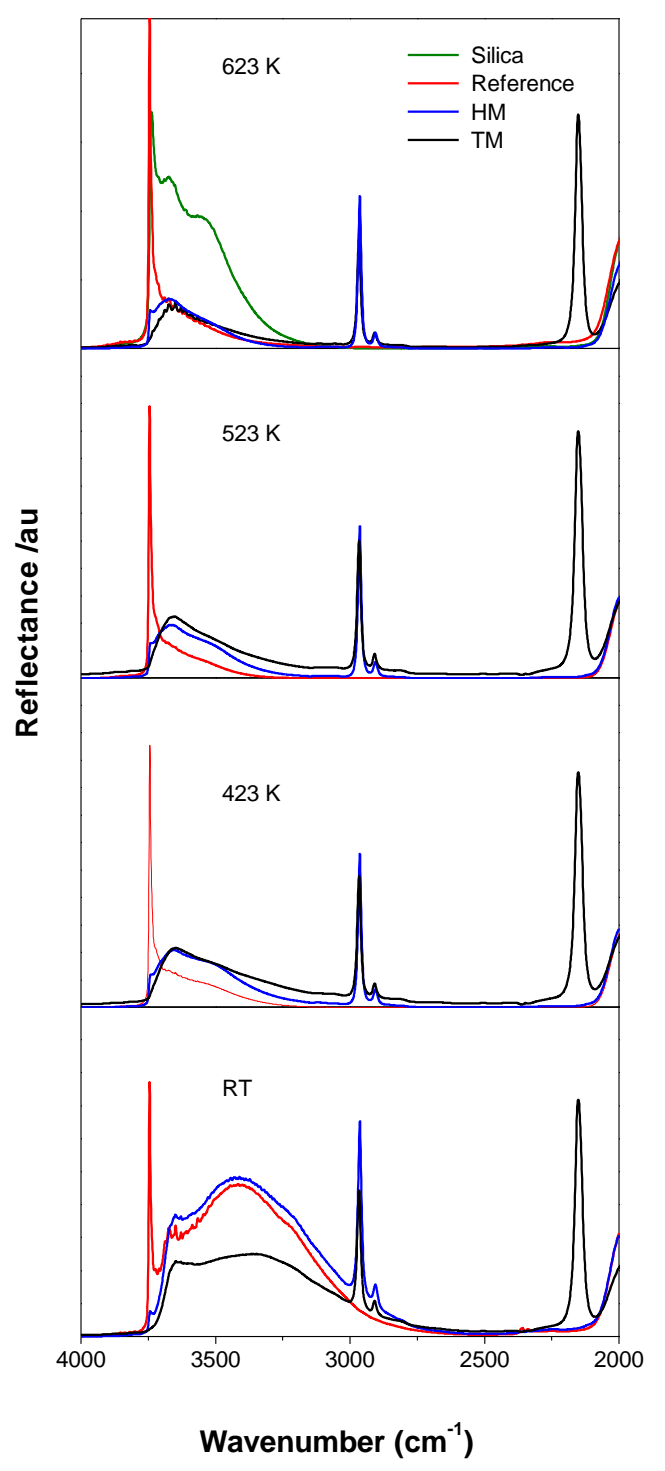

Figure 2 


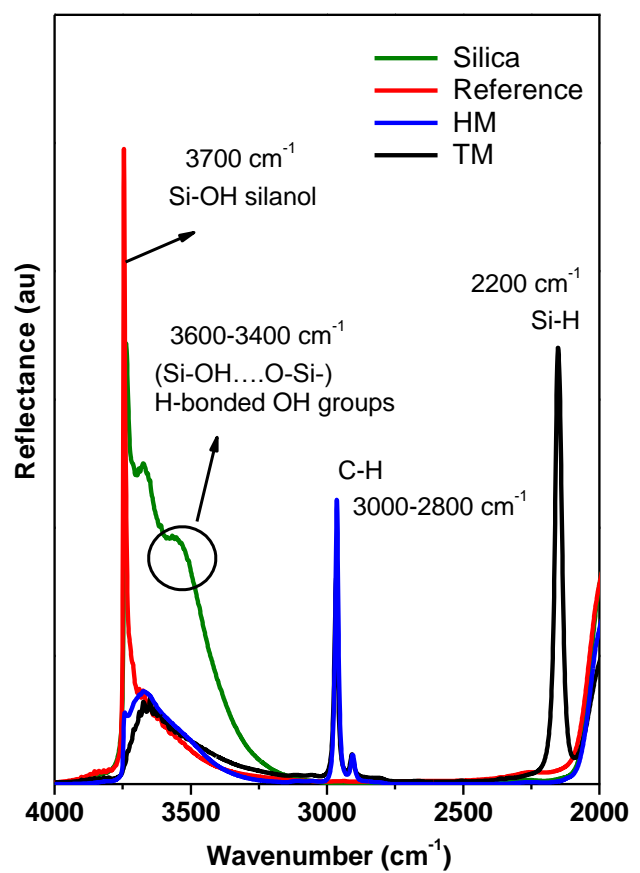

Figure 3 


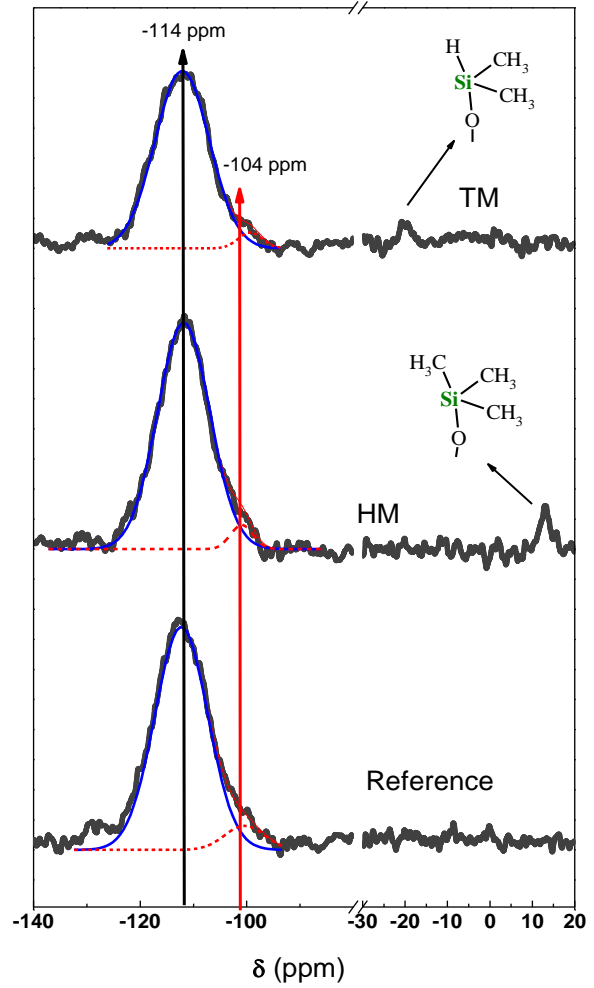

Figure 4 


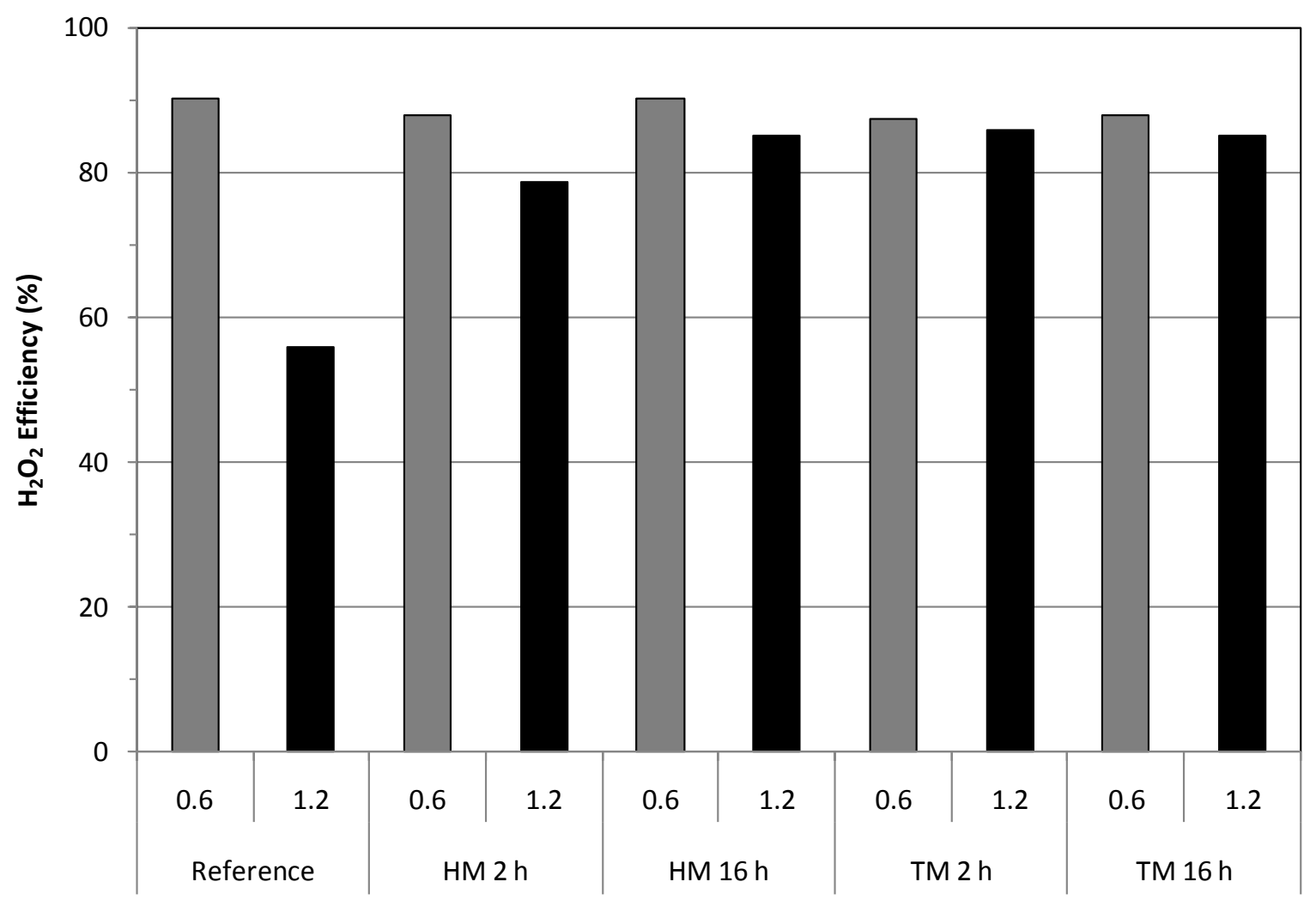

Figure 5 


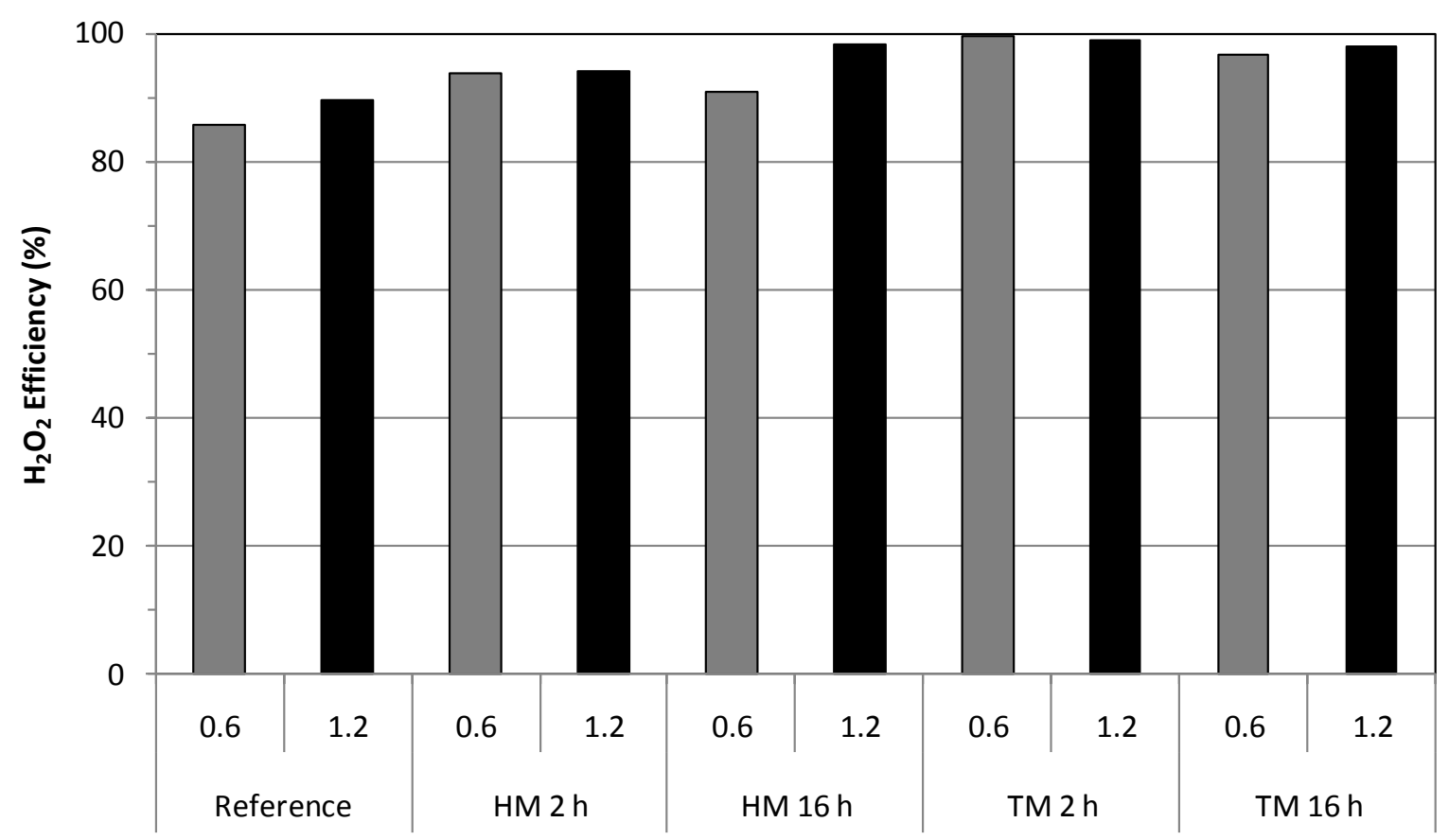

Figure 6 


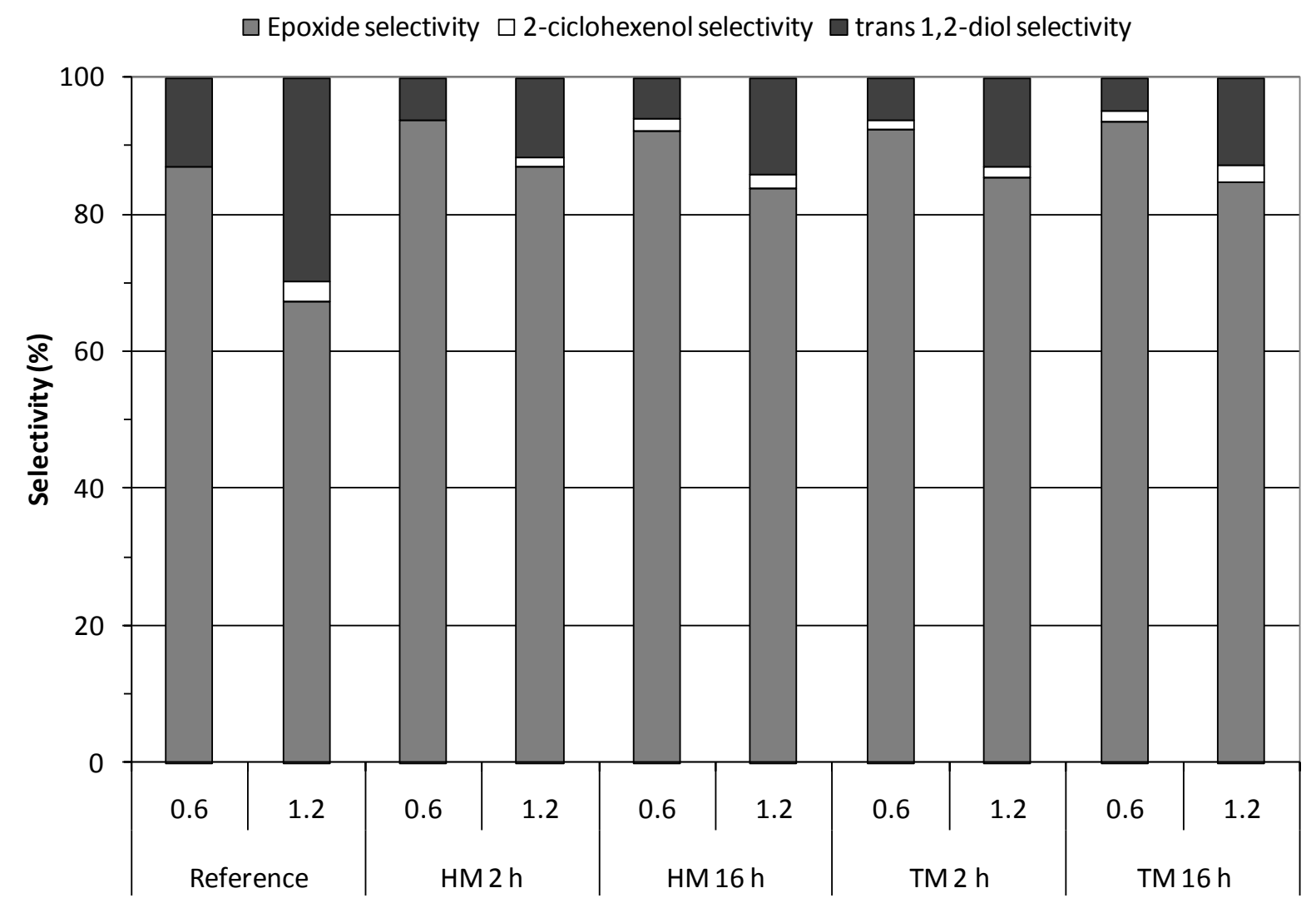

Figure 7 